\title{
Effect of Regular Exercise on Anxiety and Self-Esteem Level in College Students
}

\author{
Zahra Hamidah, ${ }^{1}$ Putri Teesa Radhiyanti Santoso, ${ }^{2}$ RM. Haryadi Karyono ${ }^{3}$ \\ ${ }^{1}$ Faculty of Medicine Universitas Padjadjaran, ${ }^{2}$ Department of Physiology Faculty of Medicine, \\ Universitas Padjadjaran/Dr. Hasan Sadikin General Hospital Bandung, ${ }^{3}$ Department of Psychiatry, \\ Faculty of Medicine Universitas Padjadjaran/Dr. Hasan Sadikin General Hospital Bandung
}

\section{Abstract}

Background: Regular exercise is often presented as an effective tool to influence the psychological aspect of a human being. Recent studies show that anxiety and self-esteem are the most important psychological aspects especially in college students. This study aimed to determine the differences of anxiety and selfesteem level between students who joined and did not join regular exercise program, Pendidikan Dasar XXI Atlas Medical Pioneer (Pendas XXI AMP), in the Faculty of Medicine, Universitas Padjadjaran.

Methods: A cross-sectional comparative study was carried out to 64 students who joined and did not join Pendas XXI AMP. Thirty six students (12 females and 20 males) who joined Pendas XXI AMP participated in aerobic and anaerobic exercise sessions lasting for 30 minutes per session, three times in 5 months. The control group was 32 students who did not join Pendas XXI AMP, with matching gender composition as the case group (12 females and 20 males). Two questionnaires, Zung Self-Rating Anxiety Scale questionnaire and Rosenberg's Self-Esteem Scale questionnaire, were administered to both groups. The data were analyzed using chi-square test $(\alpha=0.05)$.

Results: : There were statistically significant differences in anxiety level $(p=0.016)$ and self-esteem level $(\mathrm{p}=0.039)$ between case and control groups. The students who joined Pendas XXI AMP have lower anxiety and higher self-esteem levels.

Conclusions: Planned, structured, and repeated physical activities have a positive influence in anxiety and self-esteem levels. [AMJ.2015;2(3):429-32]

Keywords: Anxiety, Rosenberg's Self-Esteem Scale, self-esteem, Zung Self-Rating Anxiety Scale

\section{Introduction}

Exercise and physical activity have different meanings, physical activity is motion of body produced by muscles and produces increasing out of energy, whereas exercise is planned, structured, and repeated physical activity which has the objectives to improve health. ${ }^{1}$ Previous related studies revealed that regular exercise has benefits for health not only physiological aspect but also psychological aspect. $^{2}$

Anxiety and self-esteem are very important psychological aspects especially in college students. Anxiety is defined as an alerting signal that warns of danger and enables a person to take measures to treat an unknown threat, internal vague, or conflictual. ${ }^{3}$ It is also defined as an uneasy feeling about something threatening but vague event. ${ }^{4}$ This is a normal and adaptive response to something threatening, but can be pathologist if it happens severely or in the long term. ${ }^{5}$

Self-esteem is defined as a measurement of self-value based on her/his successes. ${ }^{3}$ In addition, self-esteem is a combination of self-respect and self-confidence which can stimulate self-motivation to reach the purpose. Self-esteem can be enhanced also by exercise with influencing the way a person thinks about body image, and also exercise can increase neurotransmitter concentration in brain by stimulating sympathetic nerves. Both exercise and self-esteem have important roles in improving quality of human resources and also in increasing their productivity. ${ }^{6}$

Correspondence: Zahra Hamidah, Faculty of Medicine, Universitas Padjadjaran, Jalan Raya Bandung-Sumedang Km.21, Jatinangor, Sumedang, Indonesia, Phone: +62 85721226847 Email: zahrahamidah@yahoo.co.id 
Table 1 Anxiety Level of Students who Joined and did not Join Pendas XXI AMP based on ZSAS (Zung Self-Rating Anxiety Scale)

\begin{tabular}{lcc}
\hline & & Anxiety Level \\
& Anxious & Not Anxious \\
\hline Joined Pendas XXI AMP & $3(9.4 \%)$ & $29(90.6 \%)$ \\
Did not Join Pendas XXI AMP & $11(34.4 \%)$ & $21(65.6 \%)$ \\
\hline
\end{tabular}

The optimal exercise recommended by the reference is performed at least performed during three months, three times a week, and twenty minutes each session. ${ }^{7,8}$ At the Faculty of Medicine Universitas Padjadjaran, there is an extracurricular known as Atlas Medical Pioneer (AMP) which performs a program named Pendidikan Dasar Atlas Medical Pioneer (Pendas AMP) every two year. In 2012, the program Pendas XXI AMP performed exercise programs for approximately five months, three times a week, and at least thirty minutes exercise each session. Therefore, the researcher wants to know the differences of anxiety and self-esteem levels between students who joined and did not join Pendas XXI AMP at the Faculty of Medicine Universitas Padjadjaran.

\section{Methods}

A cross-sectional comparative study was carried out to 64 students who joined and did not join Pendas XXI AMP. Thirty two students (12 female and 20 male) who joined Pendas XXI AMP participated in the aerobic and anaerobic exercise session lasting 30 minutes per session, three times a week for 5 months.

The control group was 32 students who did not join Pendas XXI AMP, taken randomly with adjusted amount of subjects with the first group (12 female and 20 male). The inclusion criteria were students in Faculty of Medicine Universitas Padjadjaran, having good health, and were ready to fillthe informed consent and questionnaires, whereas theexclusion criteria were students who attending a regular exercise program besides Pendas XXI AMP and did not fill all of the questionnaire, and did not return the questionnaires.

Two questionnaires i.e. the Zung Self-Rating Anxiety Scale questionnaire and Rosenberg's Self-Esteem Scale questionnaire, were given to both groups to be filled completely. The Zung Self-Rating Anxiety Scale questionnaire consisted of 20 items with a range of total scores of 20-80, while the Rosenberg's SelfEsteem Scale questionnaire consisted of 10 items with a range of total scores of $0-30$. The reliability and validity of the questionnaires were found to be acceptable. The data were analyzed using chi-square test $(\alpha=0.05)$. This study received the approval of the Head of Dewan Pengurus XIX Atlas Medical Pioneer, and Health Research Ethics Committee Faculty of Medicine Universitas Padjadjaran.

\section{Results}

Subjects consisted of 64 students and were ranging in age from 17-22 years old. These subjects were divided into two groups, students who joined Pendas XXI AMP as the study group $(\mathrm{n}=32)$ and students who did not join Pendas XXI AMP as the control group $(n=32)$. Both groups had the same numbers of gender. There were 12 female students and 20 male students in each group. Based on the Zung Self-Rating Anxiety Scale, Table 1 shows that the number of people who were anxious in the study group (9.4\%) were less than in the control group (34.4\%).

Table 2 Self-esteem Level of Students who Joined and did not join Pendas XXI AMP based on RSES (Rosenberg's Self-Esteem Scale Questionnaire)

\begin{tabular}{lcc}
\hline & \multicolumn{2}{c}{ Self-Esteem Level } \\
& Low & Normal \\
\hline Joined Pendas XXI AMP & $2(6.3 \%)$ & $30(93.7 \%)$ \\
Did not Join Pendas XXI AMP & $8(25 \%)$ & $24(75 \%)$ \\
\hline
\end{tabular}


To obtain a significant result, this study compared the anxiety level the self-esteem level of the study group to control group using chi-square test. The result showed the significant difference $(p=0.016)$ which meant the anxiety level of students who joined Pendas XXI AMP were lower than of students who did not join Pendas XXI AMP.

Based on the Rosenberg's Self-Esteem Scale questionnaire, Table 2 shows that the number of people who had low self-esteem level in the study group $(6.3 \%)$ were less than in the control group (25\%).

Finally, to obtain a significant result of the researcher compared the self-esteem level of the study group to the control group using chi-square test, and the result showed the significant difference $(p=0.039)$ which meant self-esteem level of students who joined Pendas XXI AMP were higher than of students who did not join Pendas XXI AMP.

\section{Discussion}

Based on the Zung's Self-Rating Anxiety Scale and Rosenberg's Self-Esteem Scale questionnaires, the results showed that students who joined Pendas XXI AMP had higher anxiety and self-esteem levels compared to students who did not join Pendas XXI AMP. This result is appropriate to the research hypothesis because Pendas XXI AMP had a regular exercise program, but there are several other factors affecting anxiety and self-esteem which the researcher did not consider such as genetic, age, family, education level, endocrine variations, and environmental condition.

Many references and studies describe the benefits of regular exercise to psychological aspects, including anxiety and self-esteem. One of the references explains about the benefits of exercise which are significantly reducing depression and anxiety levels by diverting attention far from the sources of depression and anxiety. Another benefit of exercise is increasing of self-esteem as the increasing of body satisfaction is associated with general self-esteem and confidence. ${ }^{1}$ Regular exercise has an effect also on producing hormone known as endorphine, which stimulates serotonin to work in the limbic system and has a role as an emotion regulator. Additionally, serotonin is an important neurotransmitter that is effective in reducing anxious and frightened symptoms. Moreover, endorphine has the same chemical structure as morphine and produces an effect that is known as runner's high which means a very glad feeling and is usually described as euphoric sensation or altered state of consciousness. This explains also why endorphin can alter the level of consciousness with reducing response to external stimulus. Besides, exercises can increase the neurotransmitter concentration in the brain by stimulating sympathetic nerves, as well as influencing physiological aspect to better mental health. ${ }^{6}$

From some similar studies conducted, four hundred elderly people were randomly assessed with the intervention group who had exercises twice a week for two months, and the result was that intervention showed significant effect to prevent mental disorder such as anxiety, social dysfunction, depression, and somatization symptoms. ${ }^{10}$ Another research conducted to forty three subjects aimed to observe the correlation between exercise and self-esteem showed there was positive significant correlation. The correlation between exercise and self-esteem is described by increasing the subjects' comprehension of the importance of common health. ${ }^{11}$ The effect of regular exercise to psychological aspect has ever been compared to other activities such as relaxation, health education, social contact, and other activities which had the purpose to distract the mind from anxiety, depression, and also to increase self-esteem. The result was regular exercise has the same effective way as the other activities in giving benefits to psychological aspects. ${ }^{6}$

The limitation of this study was it did not consider other factors that contributed to the level of anxiety and self-esteem.

In conclusion, this study reveals that there is a significant difference $(\mathrm{p}=0.016)$ in anxiety level of students who join Pendas XXI AMP, who have lower anxiety level than students who do not join Pendas XXI AMP. In addition, there is a significant difference also in self-esteem level $(p=0.039)$ of students who join Pendas XXI AMP who have higher self-esteem level than students who do not join Pendas XXI AMP. Finally, enhancing good psychological aspect regular exercise is recommended, because not only psychological but regular exercise also has benefits to physiological aspects, for a better quality of life.

\section{References}

1. Odgen J. Health psychology. 3rd ed. New York City: McGraw-Hill International; 2004.

2. Cohen GE, Shamus E. Depressed, low self-esteem: what can exercise do for 
you?. Internet J Allied Health Sci Pract. 2009;7(2).

3. Sadock BJ, Kaplan HI, Sadock VA. Kaplan \& sadock's synopsis of psychiatry: behavioral sciences/clinical psychiatry. 10th ed. Philadelphia: Lippincott Williams \& Wilkins and Wolter Kluwer Health; 2007.

4. Rachman SJ. Anxiety. In: Brewin CR, editors. The nature of anxiety. 2nd ed. New York: Psychology Press; 2004. p. 3.

5. Semple D, Smyth R. Oxford handbook of psychiatry. 1st ed. Oxford: Oxford University Press; 2005.

6. Craft LL, Perna FM. The benefits of exercise for the clinically depressed. J Clin

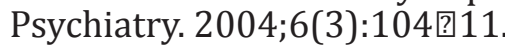

7. Haskell WL, Lee IM, Pate RR, Powell KE, Blair SN, Franklin BA, et al. Physical activity and public health: updated recommendation for adults from the american college of sports medicine and the american heart association. Med Sci Sports Exerc. 2007;39(8):1423?34.

8. Whitelaw S, Swift J, Goodwin A, Clark D. Physical activity and mental health: the role of physical activity in promoting mental wellbeing and preventing mental health problems: an evidence briefing. Edinburgh: NHS Health Scotland; 2008.

9. Dahlan MS. Statistik untuk kedokteran dan kesehatan. 5th ed. Jakarta: Salemba Medika; 2011.

10. Seyede S, Kazem M, Hassan E. Mental disorder prevention and physical activity in Iranian elderly. Int J Prev Med. 2012;3 (Suppl1):S64国S72.

11. Misraa R, Alexyb B, Panigrahi B. The relationships among self-esteem, exercise, and self-rated health in older women. J Women Aging. 2008;8(1):81国94. 